\title{
Estimating tooth retention by the number of present teeth in a middle-old-aged population: 3-year follow-up study in Korea
}

\section{Prognoza zachowania zębów na podstawie liczby obecnych zębów w populacji w wieku średnim - 3-letnie badanie kohortowe w Korei}

\author{
Ga-Yeong Lee ${ }^{1, A-D, F}$, Sang-Baek Koh ${ }^{2,3, A, E, F}$, Nam-Hee Kim ${ }^{4, A, C, E, F}$ \\ 1 Department of Dental Hygiene, Graduate School, Yonsei University, Seoul, Korea \\ ${ }^{2}$ Department of Preventive Medicine, Wonju College of Medicine, Yonsei University, Korea \\ ${ }^{3}$ Institute of Genomic Cohort, Yonsei University, Wonju, Korea \\ ${ }^{4}$ Department of Dental Hygiene, Wonju College of Medicine, Yonsei University, Korea
}

A - research concept and design; $\mathrm{B}$ - collection and/or assembly of data; $\mathrm{C}$ - data analysis and interpretation;

$D$ - writing the article; $E$ - critical revision of the article; $F$ - final approval of the article

Address for correspondence

Nam-Hee Kim

E-mail: nami71@yonsei.ac.kr

Funding sources

None declared

Conflict of interest

None declared

\section{Acknowledgments}

We sincerely thank 13 dental hygiene researchers who collected data from 2010 to 2014: Bo-Hyeon Ku, Hyo-Won Kim, Min-Young Lee, Hye-Yeon Seo, Ji-Eun Jeon, Hyun-Kyung Kim, Ji-Hyun Beack, Da-Yee Jeung, Yeun-Ju Kim, Eun-Mi Choi, Seong-Hyeon Chae, Hee-Jin Kim, and A-Ram Lee.

Received on 0ctober 11, 2017

Reviewed on November 10, 2017

Accepted on December 6, 2017

DOI

$10.17219 / \mathrm{dmp} / 81033$

Copyright

() 2018 by Wroclaw Medical University

and Polish Dental Society

This is an article distributed under the terms of the

Creative Commons Attribution Non-Commercial License

(http://creativecommons.org/licenses/by-nc-nd/4.0/)

\begin{abstract}
Background. The number of individual teeth decreases with age, resulting in a decrease in masticatory capacity, and is an important indicator of oral health. However, it is difficult to estimate the number of present teeth on the basis of age alone.

Objectives. We aimed to determine whether tooth retention could be estimated by the number of present teeth in middle-old-aged individuals.

Material and methods. We used data from the Korean Genome and Epidemiology Study on Atherosclerosis Risk of Rural Areas in the Korean General Population (KoGES-ARIRANG). Subjects ( $40-75$ years old) were invited to participate in a 3-year prospective follow-up survey conducted from 2010 to 2014 . A total of 557 individuals (219 men and 338 women) took part in the study. Tooth retention was estimated from the number of present teeth by multivariate logistic regression analysis using SPSS v 20.0 .
\end{abstract}

Results. In total, 294 (52.8\%) subjects retained teeth during a 3-year follow-up period. The number of present teeth and the proportion of subjects with complete tooth retention after 3 years decreased with increasing age. A greater number of present teeth in the baseline year was associated with complete tooth retention after 3 years in a greater proportion of subjects $(p<0.001)$. Logistic regression analysis revealed that the proportion of subjects with tooth retention in the Q4 quartile (28 teeth) was 9.17 times that in the Q1 quartile (less than 26 present teeth), even after adjusting for sociodemographic factors and oral health behavior in middle-aged individuals. In elderly individuals, tooth retention in the Q4 quartile (28 teeth) was 4.50 times that in the 01 quartile (less than 17 teeth).

Conclusions. The number of present teeth could be used to estimate tooth retention over a 3-year period. This highlights the importance of promoting oral health care in middle-aged individuals before tooth loss occurs.

Key words: oral health, tooth loss, cohort study, preventive dentistry

Słowa kluczowe: stan zdrowia jamy ustnej, utrata zębów, badanie kohortowe, stomatologia prewencyjna 


\section{Introduction}

The number of teeth is an important indicator of oral health, particularly in the elderly population. The number of teeth decreases with age, resulting in a decrease in masticatory capacity. ${ }^{1}$ Elderly individuals often choose to use a dental prosthesis, such as dentures or implants, to compensate for the loss of masticatory capacity. ${ }^{2,3}$ However, these prostheses do not always fully restore mastication, and patients still experience discomfort. ${ }^{4-6}$ Consequently, elderly patients commonly limit or exclude certain food items from their diet, ${ }^{7}$ which leads to malnutrition and an increased risk of systemic disease. ${ }^{8}$ The number of teeth is also associated with accurate pronunciation during speech. ${ }^{9}$ Elderly individuals with few present teeth have difficulties in pronunciation, which could lead to social exclusion. These findings indicate that tooth loss can lead to a decrease in the quality of life in elderly individuals. ${ }^{10,11}$ Therefore, retaining present teeth by preventing tooth loss is necessary for maintaining health during old age.

There have been many studies on the risk factors associated with tooth loss. Both sociodemographic factors, such as age, sex, marital status and cohabitation status, ${ }^{12,13}$ as well as socioeconomic factors, such as educational level and income level, ${ }^{14,15}$ have been associated with tooth loss. Poor lifestyle habits, ${ }^{16}$ including smoking and drinking, and poor oral health behavior (e.g., improper tooth brushing, lack of deep cleaning and lack of dental checkups $)^{17}$ have also been associated with tooth loss. However, recently, the paradigm has shifted from identifying risk factors of disease to investigating disease-prevention factors. ${ }^{16-19}$ Evidence has accumulated showing that prevention factors could help healthy people retain a healthy status. ${ }^{20,21}$ From the perspective of oral health, it is important to investigate the factors preventing tooth loss.

The number of present teeth is associated with age and is an important indicator of oral health; ${ }^{22,23}$ however, it is difficult to estimate the number of present teeth on the basis of age alone. A previous study reported that the number of present teeth in individuals at the ages of 50-59 years and 56-65 years was associated with tooth loss 6 years later. ${ }^{24}$ However, in that study, it was not possible to estimate future tooth retention from the number of present teeth at baseline, because the authors used 2 separate cross-sectional or longitudinal studies to examine the effect of present teeth on tooth loss, but did not investigate the issue from the perspective of tooth retention.

\section{Objectives}

The aim of this 3-year prospective cohort study was to determine if tooth retention in elderly individuals could be estimated from the number of present teeth during middle age.

\section{Material and methods}

\section{Study design and participants}

The study protocol was approved by the Institutional Review Board of Wonju Christian Hospital in Korea (CR105024-026). All participants provided written informed consent.

We used data from the Korean Genome and Epidemiology Study on Atherosclerosis Risk of Rural Areas in the Korean General Population (KoGES-ARIRANG), which is a population-based, prospective cohort study assessing the prevalence of and risk factors for systemic and dental disease. In 2005, the KoGES-ARIRANG recruited individuals residing in rural Wonju in South Korea. Demographic shifts in the 8 districts involved are infrequent, and the population could thus be followed over a long time. The population was invited to participate in this study through the media, conferences, and telephone calls, among other methods. ${ }^{25}$

The survey was performed between March 2010 and August 2014 and included 1,726 adults (711 men and 1,015 women), aged 40-75 years, who underwent an oral examination and interview. Out of these, 899 (52.1\%) subjects were selected for the study. We then excluded 296 subjects with an error in the number of lost teeth, $35(3.9 \%)$ subjects who were edentulous at baseline, and 11 (1.2\%) outliers who lost more than 9 teeth for unknown reasons during the follow-up period. The final sample size for the present analysis was 557 participants (219 men and 338 women) (Fig. 1). The participants completed a standardized dental history and lifestyle questionnaire, and underwent a comprehensive oral examination including counting the number of present teeth according to standard procedures at baseline and follow-up examinations.

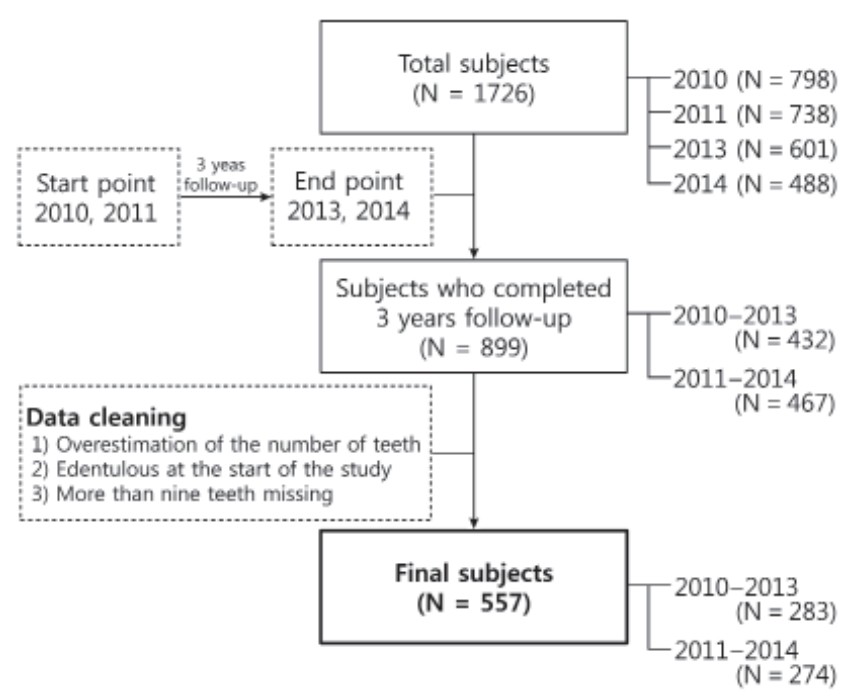

Fig. 1. Selection of study population 


\section{Main outcome and exposure measures}

The main outcome measure was tooth retention, i.e., without the loss of 1 or more teeth, during the 3 years following the baseline year. The main exposure variable was the number of present teeth. Present teeth were operationally defined as functional teeth with crowns and roots, excluding dental implants, dentures, and pontics. The number of present teeth was counted by trained dental hygienists. Trained dental hygienists also carried out the oral examination, using a tongue depressor, with the subjects seated on a chair.

\section{Covariates}

Sociodemographic variables were based on questions used during the interview: "What is the level of your education?" (elementary school or lower, middle school, high school or higher); "What is your marital status?" (married or unmarried, including being divorced and widowed); and "Who do you live with now?" (alone, with a spouse, with children).

Oral health behavioral variables were based on the following questions: "How many times did you brush your teeth yesterday?"; "Do you use any additional oral hygiene devices, such as dental floss or an interdental brush, mouth rinse products, an electronic toothbrush, or a waterpik?"; "Have you visited a dental clinic within the last 3 years?"; and "If so, what type of treatment did you receive?" (no treatment, oral examination, dental scaling and periodontal treatment, restorative treatment, endodontic treatment, prosthetics treatment, dental implant, or not sure). In the present study, we only analyzed the responses on prevention treatment, such as dental scaling and oral examination, i.e., we did not include the data on the other treatment types. Two to 4 weeks after the survey, the surveyor randomly invited $20 \%$ of the initial participants to complete the survey again, in order to evaluate test-retest reliability; the kappa $\kappa$ value was 0.967 .

\section{Statistical analysis}

In this study, as there were significant differences in the sociodemographic and baseline oral health characteristics between different age groups, the population was divided into "middle" ( $<60$ years) and "older" ( $\geq 60$ years) age groups for analysis.

A $\chi^{2}$ analysis was performed to determine differences in tooth retention distribution according to the quartiles for the number of present teeth after the baseline year. A multivariate logistic regression analysis was used to identify the factors associated with tooth retention, and the odds ratio (OR) and 95\% confidence interval (CI) were calculated. A crude model and 3 models adjusted for covariates were used to investigate how the number of present teeth in the baseline year affected tooth retention. The magnitude of the effect of exposure variables on tooth retention was identified using the crude model. Similarly, model 1 was used to iden- tify the effects of exposure variables on tooth retention after adjusting for the sociodemographic characteristics; model 2 - after adjusting for oral health behavior; and model 3 - after adjusting for sociodemographic characteristics and oral health behavior. All statistical analyses were performed using SPSS v. 20.0 for Windows (IBM Corp., Armonk, USA), and a p-value $<0.05$ was considered statistically significant.

\section{Results}

\section{Participant characteristics}

The mean age of the 557 participants at baseline was $57.9 \pm 8.14$ years (men: 59.5 years; women: 56.9 years); more women $(n=338,60.7 \%)$ than men $(n=219,39.3 \%)$ took part in the study. The sociodemographic characteristics of the participants are listed in Table 1.

Table 1. Sociodemographic and oral health behavior characteristics of subjects in the baseline year

\begin{tabular}{|c|c|c|}
\hline \multicolumn{2}{|c|}{ Variables } & $\mathrm{n}(\%)$ \\
\hline \multicolumn{2}{|l|}{ Total } & $557(100.0)$ \\
\hline \multicolumn{3}{|c|}{ Sociodemographic characteristics } \\
\hline \multirow{2}{*}{ Sex } & male & $219(39.3)$ \\
\hline & female & $338(60.7)$ \\
\hline \multirow{4}{*}{ Age [years] } & $40-49$ & $95(17.1)$ \\
\hline & $50-59$ & $233(41.8)$ \\
\hline & $60-69$ & $177(31.8)$ \\
\hline & $\geq 70$ & $52(9.3)$ \\
\hline \multirow{3}{*}{ Educational level } & elementary school or lower & $190(34.1)$ \\
\hline & middle school & $102(18.3)$ \\
\hline & high school or higher & $265(47.6)$ \\
\hline \multirow{2}{*}{ Marital status } & married & $513(92.1)$ \\
\hline & unmarried & $44(7.9)$ \\
\hline \multirow{3}{*}{ Cohabitation status } & alone & $34(6.1)$ \\
\hline & with a spouse & $279(50.1)$ \\
\hline & with children & $244(43.8)$ \\
\hline \multicolumn{3}{|c|}{ Oral health behavior } \\
\hline \multirow{3}{*}{ Daily tooth brushing } & at least once & $59(10.6)$ \\
\hline & twice & $304(54.6)$ \\
\hline & 3 or more times & $194(34.8)$ \\
\hline \multirow{2}{*}{$\begin{array}{l}\text { Using oral hygiene } \\
\text { devices }\end{array}$} & yes & $184(33.0)$ \\
\hline & no & $373(67.0)$ \\
\hline \multirow{2}{*}{$\begin{array}{l}\text { Visit to a dental clinic } \\
\text { within } 3 \text { years }\end{array}$} & yes & $384(68.9)$ \\
\hline & no & $173(31.1)$ \\
\hline \multirow{2}{*}{$\begin{array}{l}\text { Oral examination } \\
\text { within the last } 3 \text { years }\end{array}$} & yes & $80(14.4)$ \\
\hline & no & 477 (85.6) \\
\hline \multirow{2}{*}{$\begin{array}{l}\text { Dental scaling within } \\
\text { the last } 3 \text { years }\end{array}$} & yes & $142(25.5)$ \\
\hline & no & $415(74.5)$ \\
\hline
\end{tabular}

The data was analyzed with a frequency analysis. 
Out of the 557 participants, 294 (52.8\%) subjects did not lose any further teeth during the 3-year follow-up period. The mean number of present teeth at baseline was $24.33 \pm 6.45$; the mean number of present teeth in the following year was $22.79 \pm 7.47$, and the mean number of lost teeth was $1.54 \pm 2.53$.

\section{Tooth retention according to the number of present teeth at baseline}

The number of present teeth at baseline in the age group 40 to 49 was 27.4 , and that in the $\geq 70$ age group was 20.7 . After 3 years, $68.4 \%$ of the age group 40 to 49 at baseline and $30.8 \%$ of the age group $\geq 70$, respectively, retained all of their teeth. These findings indicate that the number of present teeth and the proportion of subjects with complete tooth retention after 3 years decreased with age (Fig. 2).

The distribution of present teeth in middle-aged individuals ( $<60$ years) is shown in Table 2 . For this analysis, we grouped the participants into quartiles $\left(\mathrm{Q}_{1,2,3,4}\right)$ according to the number of present teeth at baseline. A higher num-

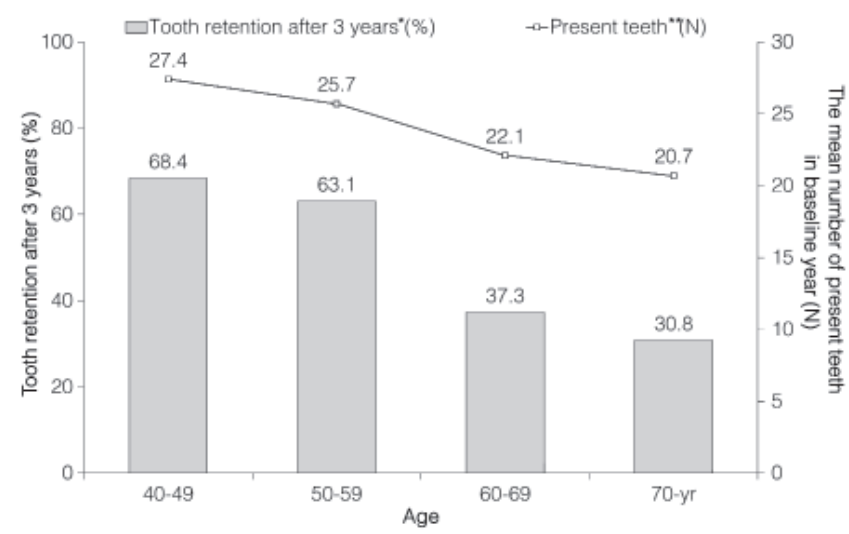

Fig. 2. Present teeth in the baseline year and tooth retention 3 years later

* tooth retention after 3 years means no tooth loss during the 3 years

of follow-up; ** present teeth means the mean number of present teeth in the baseline year.

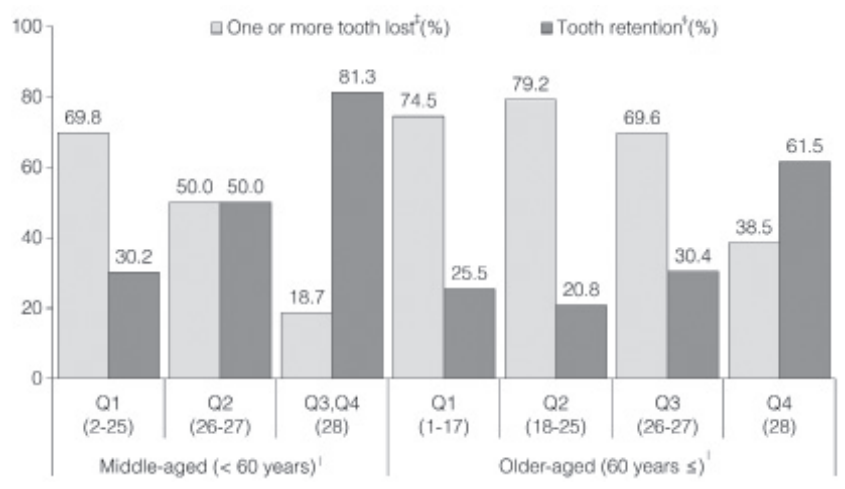

Fig. 3. Tooth retention after 3 years according to the number of present teeth in the baseline year

${ }^{\dagger}$ difference in tooth retention according to the quartile of present teeth using $x^{2}$ tests $(p<0.001) ;{ }^{\ddagger}$ one or more teeth lost $(\%)$ represents the proportion of subjects who lost 1 or more teeth during the 3-year follow-up; $\S$ tooth retention (\%) represents the proportion of subjects who did not lose 1 or more teeth during the 3-year follow-up.

ber of present teeth at baseline was associated with better tooth retention after 3 years $(\mathrm{p}<0.001)$. In $\mathrm{Q}_{3,4} 81.3 \%$ of the subjects showed complete tooth retention, i.e., the proportion of subjects with no tooth loss was greater than that of subjects with the loss of 1 or more teeth (Table 2, Fig. 3).

The distribution of present teeth in older individuals ( $\geq 60$ years) is also shown in Table 2 . Similar to the middle-aged individuals, a higher number of present teeth at baseline was associated with better tooth retention after 3 years ( $\mathrm{p}<0.001)$. In $\mathrm{Q}_{4}, 61.5 \%$ of subjects showed complete tooth retention, i.e., the proportion of subjects with no tooth loss was greater than the proportion of subjects with the loss of 1 or more teeth (Table 2, Fig. 3).

\section{Association between tooth retention and the number of present teeth in the baseline year}

In the middle-aged group, there was an association between tooth retention after 3 years and the number of present teeth at baseline in the $\mathrm{Q}_{3,4}$ group, after ad-

Table 2. Quartiles of present teeth by patient age group and tooth retention

\begin{tabular}{|c|c|c|c|c|c|}
\hline \multirow{2}{*}{$\begin{array}{l}\text { Quartiles of present teeth in the baseline } \\
\text { year (the number of teeth) }\end{array}$} & \multirow{2}{*}{ n (\%) } & \multirow{2}{*}{ Mean $\pm \mathrm{SD}^{+}$} & \multicolumn{3}{|c|}{ Tooth retention after 3 years } \\
\hline & & & no & yes & $\mathrm{p}$-value $\mathrm{e}^{\ddagger}$ \\
\hline Middle-aged (<60 years) & - & $26.16 \pm 4.18$ & - & - & $<0.001$ \\
\hline total & - & - & $212(64.6)$ & $116(35.4)$ & - \\
\hline $\mathrm{Q}_{1}(2-25)$ & $63(19.2)$ & - & $44(69.8)$ & $19(30.2)$ & - \\
\hline$Q_{2}(26-27)$ & $72(22.0)$ & - & $36(50.0)$ & $36(50.0)$ & - \\
\hline $\mathrm{Q}_{3}, \mathrm{Q}_{4}(28)$ & $193(58.8)$ & - & $36(18.7)$ & $157(81.3)$ & - \\
\hline Older-aged ( $\geq 60$ years) & - & $21.70 \pm 8.05$ & - & - & $<0.001$ \\
\hline total & - & - & $82(35.8)$ & $147(64.2)$ & - \\
\hline $\mathrm{Q}_{1}(1-17)$ & $55(24.0)$ & - & $41(74.5)$ & $14(25.5)$ & - \\
\hline$Q_{2}(18-25)$ & $53(23.1)$ & - & $42(79.2)$ & $11(20.8)$ & - \\
\hline $\mathrm{Q}_{3}(26-27)$ & $56(24.5)$ & - & $39(69.6)$ & $17(30.4)$ & - \\
\hline $\mathrm{Q}_{4}(28)$ & $65(28.4)$ & - & $25(38.5)$ & $40(61.5)$ & - \\
\hline
\end{tabular}

${ }^{\dagger}$ mean \pm SD - the mean number of present teeth and standard deviation; ${ }^{\ddagger} p$-values are obtained from $x^{2}$ tests. 
Table 3. Logistic regression analysis for the association between tooth retention and present teeth during follow-up

\begin{tabular}{|c|c|c|c|c|c|c|}
\hline \multirow{2}{*}{\multicolumn{2}{|c|}{ Quartiles of natural teeth in the baseline year }} & \multicolumn{5}{|c|}{ Tooth retention after 3 years } \\
\hline & & $Q_{1}(2-25)$ & \multicolumn{2}{|c|}{$\mathrm{Q}_{2}(26-27)$} & \multicolumn{2}{|r|}{$\mathrm{Q}_{3,4}(28)$} \\
\hline \multirow{4}{*}{ Middle-aged (<60 years) } & crude model & 1 & \multicolumn{2}{|c|}{$2.32 *(1.14-4.71)$} & \multicolumn{2}{|c|}{$10.10^{* *}(5.28-19.32)$} \\
\hline & model 1 & 1 & \multicolumn{2}{|c|}{$2.01^{\text {ns }}(0.96-4.22)$} & \multicolumn{2}{|c|}{$9.55^{* *}(4.82-18.91)$} \\
\hline & model 2 & 1 & \multicolumn{2}{|c|}{$2.21 *(1.07-4.55)$} & \multicolumn{2}{|c|}{$9.70^{* *}(5.01-18.75)$} \\
\hline & model 3 & 1 & \multicolumn{2}{|c|}{$1.90^{\text {ns }}(0.89-4.04)$} & \multicolumn{2}{|c|}{$9.17^{* *}(4.60-18.30)$} \\
\hline \multirow{2}{*}{\multicolumn{2}{|c|}{ Quartiles of natural teeth in the baseline year }} & \multicolumn{5}{|c|}{ Tooth retention after 3 years } \\
\hline & & $\mathrm{Q}_{1}(1-17)$ & $Q_{2}(18-25)$ & $\mathrm{Q}_{3}(2$ & & $\mathrm{Q}_{4}(28)$ \\
\hline \multirow{4}{*}{ Older-aged ( $\geq 60$ years) } & crude model & 1 & $0.77^{\text {ns }}(0.31-1.89)$ & $1.28^{\text {ns }}(0$ & & $4.69^{* *}(2.14-10.28)$ \\
\hline & model 1 & 1 & $0.69^{\text {ns }}(0.27-1.75)$ & $1.28^{\text {ns }}(0$ & & $5.03^{* *}(2.21-11.45)$ \\
\hline & model 2 & 1 & $0.76^{\text {ns }}(0.30-1.91)$ & $0.92^{\text {ns }}(0$ & & $3.99^{* *}(1.76-9.03)$ \\
\hline & model 3 & 1 & $0.69^{\text {ns }}(0.27-1.77)$ & $1.04^{\text {ns }}(0$ & & $4.50^{* *}(1.93-10.52)$ \\
\hline
\end{tabular}

* $\mathrm{p}<0.05$; ${ }^{*} \mathrm{p}<0.001$; ${ }^{\mathrm{ns}}$ - non-significant; crude model - unadjusted; model 1 - adjusted for quartiles of present teeth in the baseline year and sociodemographic status (age, sex, educational level, marital status, cohabitation status); model 2 - adjusted for quartiles of present teeth in the baseline year and oral health behavior (tooth brushing, using dental hygiene devices, visiting dental clinic, oral examination, and dental scaling within 3 years); model 3 - adjusted for quartiles of present teeth in the baseline year, sociodemographic status, and oral health behavior.

justing for the sociodemographic characteristics (model 1). There was also a linear association after adjusting for oral health behavior (model 2). After adjusting for both sociodemographic characteristics and oral health behavior (model 3), the proportion of subjects showing complete tooth retention after 3 years in the $\mathrm{Q}_{3,4}$ group (28 teeth) was retained their present teeth about 9 times more than Q1 group (less than 26 teeth) $(\mathrm{OR}=9.17 ; 95 \%$ CI, 4.60-18.30) (Table 3).

In the older age group, there was an association in the $Q_{4}$ group between tooth retention after 3 years and the number of present teeth at baseline, even after adjusting for the sociodemographic characteristics (model 1) and oral health behavior (model 2). After adjusting for the sociodemographic characteristics and oral health behaviors (model 3), the proportion of subjects showing tooth retention after 3 years in the $\mathrm{Q}_{4}$ group (28 teeth) was retained their present teeth about 5 times more than Q1 group (less than 26 teeth) $(\mathrm{OR}=4.50 ; 95 \% \mathrm{CI}, 1.93-10.52)$ (Table 3).

\section{Discussion}

Oral rehabilitation refers to the restoration and treatment of defective teeth. ${ }^{26}$ The aim of replacing a missing tooth with a prosthesis such as an implant or a denture is to restore the esthetics and speech function of the patient. However, patients with prosthodontics have a lower ability to chew than those who have natural dentition, and hence quality of life decreases as well. ${ }^{6}$ In other words, it is preferable to preserve natural teeth rather than perform restorations.

Death is inevitable for all, even in the absence of disease. However, tooth loss due to aging is not inevitable; i.e., tooth loss is not a normal phenomenon in elderly individuals, although many studies have reported that tooth loss is an outcome of aging and that age is an indicator of tooth loss. ${ }^{22,23}$ Age alone cannot be used to predict the number of present teeth. In this prospective cohort study, we found that the number of present teeth in middleaged/elderly participants was associated with tooth retention at an older age, even after adjusting for sociodemographic status and oral health behavior. The number of present teeth might therefore help to estimate future tooth loss in elderly individuals.

The mean number of present teeth in the baseline year was $26.16 \pm 4.18$ for the middle-aged group, and $21.70 \pm 8.05$ for the elderly group. After adjusting for sociodemographic factors, such as age, sex, educational level, marital status, and cohabitation status, and for oral health behavior, such as tooth brushing, use of oral hygiene devices, oral examinations, and dental scaling, middle-aged subjects who had 28 present teeth at baseline retained 9.17 times more teeth than subjects who had $<26$ teeth. On the other hand, elderly subjects who had 28 present teeth at the baseline year retained 4.50 times more teeth than subjects who had $<18$ teeth in the baseline year. These findings suggest that the number of present teeth at baseline influenced tooth retention over the following 3 years.

Worthington et al. reported that fewer teeth at baseline was associated with greater tooth loss over 5 years in adults who regularly attended a dental clinic. ${ }^{27}$ However, after adjusting for age, sociodemographic factors and lifestyle habits, such as smoking, no significant association was observed. In a nationwide cross-sectional study, Yoshino et al. demonstrated an association between the number of present teeth and tooth loss over a period of 6 years. ${ }^{24}$ A smaller number of teeth in subjects aged 50-59 years and 56-65 years were associated with greater tooth loss after 6 years. Similarly, Eklund et al. reported that a higher percentage of subjects with fewer teeth became edentulous over a subsequent 10-year period, than did subjects with more teeth. ${ }^{28}$ 
Our results correspond with these findings: the fewer present teeth an individual had at baseline, the greater the tooth loss that person would experience over the subsequent 3 years, even after adjusting for sociodemographic status and oral health behavior, which are known factors associated with tooth loss. Therefore, age per se was not the sole indicator of tooth loss. In fact, the number of present teeth in middle age influenced tooth retention to a greater extent than the number of present teeth at an older age. However, most oral health education programs target elderly individuals rather than middle-aged individuals. In addition, dental care is often not considered a public priority for government spending. ${ }^{29}$ On the other hand, our findings suggest that preventive health policies should focus on the middle-aged or younger age groups, who have not yet experienced tooth loss.

This study has 4 notable limitations. Firstly, this study may have interview bias, as it was conducted using one-on-one interviews. The questionnaire comprised numerous questions (50), and the survey answers may have been affected by the interview environment. In addition, the participants answered the questions from memory, and recall bias may have occurred. However, the surveyors evaluated the test-retest reliability $(\kappa=0.967)$. Secondly, the study participants consisted only of middle-aged and elderly individuals living in rural Korea, so it is unclear whether the data has the representativeness of the samples. However, it has been presented that the KoGES data could be generalizable to the Korean population by comparison between the disease prevalence in the subjects from the Korean Genome and Epidemiology Study (KoGES) data and the Korea National Health and Nutrion Examination Survey (KNHANES III) data. ${ }^{30}$ Also, it should be noted that useful and meaningful data which revealed a relationship between sleep duration and the incidence of hypertension used the same data as in this study. ${ }^{25}$ Thirdly, this study considered only sociodemographic characteristics and oral health behavior variables, and other known risk factors for tooth loss, including systemic conditions, such as diabetes, cardiovascular disease, metabolic syndrome, and general health status and lifestyle factors, such as smoking and drinking habits, were not considered. Finally, the confidence interval was not precise, because this study was conducted using subgroups of middle-aged and elderly individuals; hence, the sample size was small.

Nevertheless, this study focused on tooth retention, rather than tooth loss, to determine the preventive factors for tooth loss, and investigated the association between the number of present teeth and tooth retention over a 3-year period, using cohort data after adjusting for sociodemographic status and oral health behavior. We found that the number of present teeth could be used to predict tooth retention after 3 years.

\section{Conclusions}

Our findings provide helpful information for developing a health policy for middle-aged individuals with no tooth loss; however, further studies are necessary to identify the factors underlying tooth longevity and to establish measures that can prevent tooth loss.

\section{References}

1. Zhu Y, Hollis JH. Tooth loss and its association with dietary intake and diet quality in American adults. J Dent. 2014;42:1428-1435.

2. Petricevic N, Celebic A, Rener-Sitar K. A 3-year longitudinal study of quality-of-life outcomes of elderly patients with implant and tooth-supported fixed partial dentures in posterior dental regions. Gerodontol. 2012;29:e956-e963.

3. Ćatović A, Jerolimov V, Ćatić A. Tooth loss and the condition of the prosthodontic appliances in a group of elderly home residents. J Oral Rehabil. 2000;27:199-204.

4. Higaki N, Goto T, Ishida Y, Watanabe M, Tomotake Y, Ichikawa T. Do sensation differences exist between dental implants and natural teeth? A meta-analysis. Clin Oral Implants Res. 2014;25:1307-1310.

5. Iwasaki M, Taylor GW, Manz MC, et al. Oral health status: Relationship to nutrient and food intake among 80-year-old Japanese adults. Community Dent Oral Epidemiol. 2014;42:441-450.

6. Miyaura K, Morita M, Matsuka Y, Yamashita A, Watanabe T. Rehabilitation of biting abilities in patients with different types of dental prostheses. J Oral Rehabil. 2000;27:1073-1076.

7. Daly RM, Elsner RJF, Allen PF, Burke FM. Associations between selfreported dental status and diet. J Oral Rehabil. 2003;30:964-970.

8. Wang RS, Hu XY, Gu WJ, Hu Z, Wei B. Tooth loss and risk of head and neck cancer: A meta-analysis. PLoS One. 2013;8:e71122.

9. Kim HN, Ha TG, Kim MJ, Jun EJ, Jeong SH, Kim JB. Factors related to number of present teeth in Korean elderly adults aged 55-84 years. Int J Dent Hyg. 2016;14:151-158.

10. Batista M, Lawrence $H$, Rosario de Sousa M. Impact of tooth loss related to number and position on oral health quality of life among adults. Health Qual Life Outcomes. 2014;12:165.

11. Åstrøm AN, Ekback G, Ordell S, Nasir E. Long-term routine dental attendance: Influence on tooth loss and oral health-related quality of life in Swedish older adults. Community Dent Oral Epidemiol. 2014;42:460-469.

12. Åstrøm AN, Ekback G, Lie SA, Ordell S. Life-course social influences on tooth loss and oral attitudes among older people: Evidence from a prospective cohort study. Eur J Oral Sci. 2015;123:30-38.

13. Jung SH, Ryu Jl, Jung DB. Association of total tooth loss with sociobehavioural health indicators in Korean elderly. J Oral Rehabil. 2011;38:517-524.

14. Wu B, Hybels C, Liang J, Landerman L, Plassman B. Social stratification and tooth loss among middle-aged and older Americans from 1988 to 2004. Community Dent Oral Epidemiol. 2014;42:495-502.

15. Zawada $Ł$, Matuszewska A, Chrzęszczyk D, Konopka T. Tooth loss in the adult residents of Wrocław. Dent Med Probl. 2012;49:391-398 [in Polish].

16. Morse DE, Avlund K, Christensen LB, et al. Smoking and drinking as risk indicators for tooth loss in middle-aged Danes. J Aging Health. 2014;26:54-71.

17. Zimmermann H, Zimmermann N, Hagenfeld D, Veile A, Kim TS, Becher $\mathrm{H}$. Is frequency of tooth brushing a risk factor for periodontitis? A systematic review and meta-analysis. Community Dent Oral Epidemiol. 2015;43:116-127.

18. Dhawan AP, Heetderks WJ, Pavel M, et al. Current and future challenges in point-of-care technologies: A paradigm-shift in affordable global healthcare with personalized and preventive medicine. IEEE J Transl Eng Health Med. 2015;3:1-10.

19. Garcia RI, Sohn W. The paradigm shift to prevention and its relationship to dental education. J Dent Educ. 2012;76:36-45.

20. Diener E. New findings and future directions for subjective wellbeing research. Am Psychol. 2012;67:590. 
21. Hoyt LT, Chase-Lansdale PL, McDade TW, Adam EK. Positive youth, healthy adults: Does positive well-being in adolescence predict better perceived health and fewer risky health behaviors in young adulthood? J Adolesc Health Care. 2012;50:66-73.

22. Kossioni A, Bellou O. The effect of aging and dental status on the frequency of eating out. Arch Gerontol Geriatr. 2012;54:e130-e133.

23. Renvert S, Persson RE, Persson GR. Tooth loss and periodontitis in older individuals: Results from the Swedish national study on aging and care. J Periodontol. 2013;84:1134-1144.

24. Yoshino K, Ishizuka Y, Fukai K, Takiguchi T, Sugihara N. Estimated tooth loss based on number of present teeth in Japanese adults using national surveys of dental disease. Bull Tokyo Dent Coll. 2015;56:25-31.

25. Yadav D, Hyun DS, Ahn SV, Koh SB, Kim JY. A prospective study of the association between total sleep duration and incident hypertension. J Clin Hypertens (Greenwich). 2017;19:550-557

26. Christensen GJ. Defining oral rehabilitation. J Am Dent Assoc. 2004;135:215-217.

27. Worthington $\mathrm{H}$, Clarkson J, Davies R. Extraction of teeth over 5 years in regularly attending adults. Community Dent Oral Epidemiol. 1999;27:187-194.

28. Eklund SA, Burt BA. Risk factors for total tooth loss in the United States; Longitudinal analysis of national data. J Public Health Dent. 1994;54:5-14.

29. Praveen G, Anjum S, Reddy PP, Monica M, Rao KY, Reddy AA. Public priorities for government spending on dental health care: $A$ cross sectional study. J Public Health. 2014;22:67-71.

30. YJ Kim, BG Han, the KoGES group. Cohort profile: The Korean Genome and Epidemiology Study (KoGES) Consortium. Int J Epidemiol. 2017;46:e20. 
